\title{
Políticas de formação docente: as parcerias público-privadas na rede de ensino estadual paulista
}

\author{
Ana Cristina Gonçalves de Abreu Souza ${ }^{1}$ \\ Marina Graziela Feldmann ${ }^{2}$
}

\begin{abstract}
RESUMO
Este artigo é parte de uma pesquisa de Estágio Pós Doutoral realizada no Programa Educação: Currículo da Pontifícia Universidade Católica de São Paulo que estuda as parcerias públicoprivadas nas formações dos professores da rede estadual paulista. Objetiva analisar quais as parcerias de formação estabelecidas entre a Coordenadoria da Escola de Formação e Aperfeiçoamento de Professores - Paulo Renato Costa Souza (EFAPE) e as instituições privadas nos anos de 2018 e 2019. Recorre a abordagem qualitativa empregando a pesquisa bibliográfica e análise documental. O corpo teórico embasa-se em Hernandez, Laval, Freire e Feldmann. Os resultados apontam um número crescente de parcerias entre a rede pública e instituições privadas. A racionalidade neoliberal que permeia o campo da Educação e, mais especificamente, da Formação Docente fica confirmada, exigindo, do poder público, a criação de projetos colaborativos que incluam a garantia de princípios formadores emancipatórios e críticos fortalecendo a autonomia da rede pública de ensino.
\end{abstract}

PALAVRAS-CHAVE: Formação de professores. Rede pública de ensino. Formação de professores em rede pública. Gestão educacional.

\footnotetext{
${ }^{1}$ Pós-Doutora em Educação: Currículo pela Pontifícia Universidade Católica de São Paulo - PUC-SP. Universidade Federal de Alfenas MG, Alfenas, Minas Gerais, Brasil. Orcid: http://orcid.org/0000-0003-0943-9362. E-mail: dra.anaabreu@gmail.com.

${ }^{2}$ Doutora em Educação: Currículo pela Pontifícia Universidade Católica de São Paulo - PUC-SP. Pontifícia Universidade Católica de São Paulo - PUC-SP, São Paulo, São Paulo, Brasil. Orcid: http://orcid.org/0000-00033008-2636. E-mail: feldmnn@uol.com.br.
} 
Teaching Training Policies: Public-Private Partnerships in the Education System of São Paulo State

\begin{abstract}
This article is part of a Post-doctoral Internship research in the Program Education/Curriculum from Pontifical Catholic University of São Paulo that studies public-private partnerships in the training of teachers from the São Paulo state network. It aims to analyze which are the formation partnerships established between the Coordination of the School for Formation and Improvement of Teachers - Paulo Renato Costa Souza (EFAPE) and private institutions in the years 2018 and 2019. It uses the qualitative approach employing bibliographic research and documentary analysis. The theoretical body is based on Hernandez, Laval, Freire and Feldmann. The results show an increasing number of partnerships between the public network and private institutions. The neoliberal rationality that permeates the field of Education and, more specifically, of Teacher Education is confirmed, demanding, from the public authorities, the creation of collaborative projects that include the guarantee of emancipatory and critical formative principles, strengthening the autonomy of the public school system.
\end{abstract}

KEYWORDS: Teacher formation. Public education system. Teacher formation in public system. Educational management.

Políticas de capacitación docente: alianzas público-privadas en la red de educación estatal paulista

\title{
RESUMEN
}

Este artículo es parte de una encuesta de pasantía posdoctoral realizada en el Programa de Educación: Currículo de la Pontificia Universidad Católica de São Paulo que estudia las alianzas público-privadas en la formación de docentes de la red estatal de São Paulo. Tiene como objetivo analizar cuáles són las alianzas formativas establecidas entre la Coordinación de la Escuela de Formación y Perfeccionamiento Docente - Paulo Renato Costa Souza (EFAPE) e instituciones privadas en los años 2018 y 2019. Utiliza el enfoque cualitativo empleando la investigación bibliográfica y el análisis documental. El cuerpo teórico se basa en Hernández, Laval, Freire y Feldmann. Los resultados muestran un número creciente de asociaciones entre la red pública y las instituciones privadas. La racionalidad neoliberal que impregna el campo de la Educación y, más 
específicamente, de la Formación Docente se confirma, exigiendo, desde las autoridades públicas, la creación de proyectos colaborativos que incluyan la garantía de principios formativos emancipatorios y críticos, fortaleciendo la autonomía del sistema escolar público.

PALABRAS CLAVE: Formación de profesores. Red de educación pública. Formación del profesorado público. Gestión educativa.

\section{$* * *$}

\section{Introdução}

A temática sobre formação docente tem incitado respostas e avanços nos cenários acadêmicos a fim de contribuirmos para a concepção de políticas públicas que, de fato, possam impactar diretamente na qualidade da educação pública brasileira em um contexto de exigências complexas que a contemporaneidade nos aponta para a construção de marcos teóricos e metodológicos neste campo do saber.

Este artigo se constitui a partir do estágio pós doutoral desenvolvido na Pontifícia Universidade Católica de São Paulo - PUC-SP, no Programa de PósGraduação em Educação: Currículo como produto da integração de grupos de pesquisa que têm como objeto de conhecimento a formação docente. Os estudos têm como objetivo realizar um levantamento das ações formativas propostas pela Escola de Formação e Aperfeiçoamento de Professores Paulo Renato Costa Souza (EFAPE), coordenadoria da Secretaria de Educação do Estado de São Paulo, em parceria com instituições privadas para que possamos enxergar a entrada de instituições nos cenários de formação pública. Apresentamos a seguir um recorte da pesquisa no qual abordamos as parcerias nas ações formativas propostas para a rede pública nos anos de 2018 e 2019. Estes anos foram escolhidos por revelarem os últimos dados públicos técnicos da instituição.

Nossos estudos não têm a pretensão de apontar uma padronização em relação formação desenvolvida pela Rede Estadual Paulista, mas de refletirmos sobre alguns apontamentos da formação estabelecidas pela EFAPE, mediante as parceiras, uma vez que: 
É difícil ordenar num esquema e num único discurso coerente todas as funções e formas que parcialmente o currículo adota, segundo as tradições de cada sistema educativo, de cada nível ou modalidade escolar, de cada orientação filosófica, social e pedagógica, pois são múltiplas e contraditórias as tradições que se sucederam e se misturaram nos fenômenos educativos (GIMENO SACRISTÁN, 2000, p.15).

Conforme Gimeno Sacristán (2000, p.15), compreendemos que "são múltiplas e contraditórias as tradições" que integram os processos curriculares e, portanto, formativos em seus aspectos políticos emergentes de ações públicas, estabelecidas a partir de um corpo permanente, que são compostos, por exemplo, pelos profissionais efetivos e de um corpo provisório formado por indivíduos que ocupam os cargos eletivos e de confiança, que se constituem por meio das escolhas realizadas por aqueles que foram eleitos para comporem por meio de seus mandatos governo dos estados.

Referente à formação de professores, na atualidade, estamos presenciando a crescente atuação de instituições privadas (ADRIÃO, 2018) com finalidades de mercado, assumindo a formação de docentes nas redes públicas. Isto acontece em função de respostas às demandas pela sociedade contemporânea e dos desafios e distanciamentos da construção de um processo crítico ligado a aprofundamentos de práticas educativas progressistas.

O Estado se redefine com os desafios contemporâneos mediante a racionalidade neoliberal que faz emergir as parcerias estabelecidas com as instituições privadas e suas práticas que se nutrem de concepções gerenciais e empresariais para desenvolver e executar as formações docentes. Laval (2004), em seu livro "A escola não é uma empresa: o neoliberalismo em ataque ao ensino público", evidencia a forte inclinação para que a educação formal escolar atenda à fins econômicos. Presenciamos, com clareza, a influência da linguagem e das ações empresariais nos âmbitos dos processos educativos que reproduzem estruturas de gerenciamento, metas e consumos, ao invés de mobilizar a construção e o desenvolvimento do conhecimento crítico e, consequentemente, da formação humana. 
Saberes, inovação, parcerias, tudo depende dessa lógica que tem a atração de políticas totalizantes. Esses discursos permitiram colocar, simbolicamente, a instituição escolar sob a jurisdição de uma lógica de gestão estranha à sua referência cultural e política antiga, mas também, submetê-la à pressão de lógicas econômicas que até então lhe eram exteriores, favorecendo, assim, a interiorização de novos objetivos e a constituição de novas identidades profissionais (LAVAL, 2004, p.45).

A lógica de mercado não corrobora com a lógica crítica de formação que a educação pública precisa oferecer a sociedade, pois a escola é a instituição que deve se ater a formar integralmente cidadãos críticos.

O Estado, ao longo dos anos, vem se redefinindo e alterando as fronteiras entre o público e o privado formando quase-mercados. O conceito utilizado sobre quase-mercados [...] é caracterizado por "introduzir concepções de gestão privada nas instituições públicas sem alterar a propriedade das mesmas" (OLIVEIRA; SOUZA, 2003, p.876).

A relevância da temática formação docente se evidencia no fortalecimento das políticas públicas e que incorporam diálogos acadêmicos que apontam diversos aspectos como concepções, condições de trabalho, planos de carreira e formação continuada.

Cada vez mais a questão da formação de professores assume importância ante as exigências que são colocadas diante da educação básica de crianças e de adolescentes na sociedade contemporânea. Pesquisar aspectos ligados aos cursos formadores de professores, aspectos relativos ao plano de carreira e salários, formação continuada e condições de trabalho nas escolas tornou-se importante e necessário para se conseguir lutar por mudanças que sejam essenciais e bem fundamentadas (GATTI, 2010, p.96).

Colocamos indagações sobre o processo de formação da rede estadual paulista para apontarmos pressupostos teóricos, sejam eles a serviço da manutenção de profissionais que se fortalecem como mão de obra para manter referenciais neoliberais e, por isso, com marcas de dependência intelectual contribuindo para a exploração frente ao ofício 
ou, numa outra perspectiva, a de propiciar políticas de formação emancipatórias e críticas a favor de um processo de formação que transforme e dê autonomia intelectual e moral aos profissionais.

\section{Rede de Ensino Estadual Paulista}

A Secretaria de Educação do Estado de São Paulo possui a maior rede de ensino público do Brasil, uma amplitude que engloba: 3,7 milhões de alunos, 5,4 mil unidades escolares, 242,2 mil servidores do quadro do magistério, 139,900 mil professores ativos, 4,8 mil diretores de escolas e 91 diretorias de ensino.

Em 2012 iniciou, no Estado de São Paulo, via decreto assinado pelo então Governador Geraldo Alckmin, a reestruturação da formação básica que se organiza em 2 órgãos: Conselho Estadual de Educação (CEE) e Fundação para o Desenvolvimento da Educação (FDE), e seis coordenadorias: Escola de Formação e Aperfeiçoamento de Professores - Paulo Renato Costa Souza (EFAP), Coordenadoria de Gestão da Educação Básica (CGEB), Coordenadoria de Informação, Monitoramento e Avaliação Educacional (CIMA), Coordenadoria de Infraestrutura e Serviços Escolares (CISE), Coordenadoria de Gestão de Recursos Humanos (CGRH), Coordenadoria de Orçamento e Finanças (COFI).

Considerando toda a estrutura da Rede de Educação do Estado de São Paulo nossa pesquisa estará levantando informações e dados de uma Coordenadoria específica, a investigação se dá junto a Escola de Formação e Aperfeiçoamento de Professores - Paulo Renato Costa Souza (EFAPE), órgão responsável por projetos de formação continuada para os professores.

\section{Sobre a Escola de Formação e Aperfeiçoamento de Professores - Paulo Renato Costa Souza EFAPE}

A EFAPE foi criada em 2009 pelo decreto $n^{0} 54.297$ 05/05/2009 tendo como objetivo o desenvolvimento dos servidores da Secretaria da Educação do Estado de São Paulo, nesta coordenadoria se oferece ações formativas continuadas aos servidores públicos com sede em São Paulo. A 
coordenadoria se organiza a partir de ambientes de aprendizagem físico e utiliza de estrutura tecnológica e ferramentas administrativas integradas.

Em 2019 ocorreu uma reestruturação pelo decreto no 64.187 de 17/04/2019 que altera o nome de origem EFAP para Escola de Formação e Aperfeiçoamento dos Profissionais da Educação e Aperfeiçoamento dos Profissionais da Educação do Estado de São Paulo Paulo Renato Costa Souza (EFAPE) indicando a intenção da mudança para atender todos os quadros de profissionais da secretaria incluindo os servidores municipais de Educação do Estado de São Paulo.

O setor público tem passado nos últimos anos por uma
reforma estrutural que vem alterando de forma
significativa as concepções e os objetivos que orientam as
formas de gestão e o funcionamento das instituições.
Essas reformas administrativas consolidam novos
discursos e práticas derivadas do setor privado e são
usadas como referência para organizações públicas em
todas as esferas de governo (CÓSSIO, 2018, p.67).

A formação dos professores da rede pública estadual é um ponto importante para a garantia de ações e projetos educativos a serem criados e desenvolvidos nas escolas, pois se faz necessário estabelecer ações estruturantes que fortaleçam, a partir do poder público do Estado. As reestruturações devem nascer para legitimar a força de gestão interna da Secretaria da Educação que deve estar à frente com diretrizes administrativas claras e, assim, conduzir com autonomia todo o processo de formação da rede.

\section{Caminhos Metodológicos}

O desenvolvimento metodológico da pesquisa pautou-se nos princípios qualitativos.

A abordagem da investigação qualitativa exige que o mundo seja examinado com a ideia de que nada é trivial, que tudo tem potencial para construir uma pista que nos permita estabelecer uma compreensão mais esclarecedora do nosso objeto de estudo (BOGDAN; BIKLEN, 1994, p. 49). 
Consideramos que a abordagem vai ao encontro de possibilitar esclarecimentos acerca da formação docente e de seus desdobramentos em relação a compreensão de parcerias na formação em rede públicas e as responsabilidades institucionais assumidas pela EFAPE.

Os investigadores qualitativos estabelecem estratégias e procedimentos que lhes permitam tomarem consideração as experiências do ponto de vista do informador. O processo de condução de investigação qualitativa reflete uma espécie de diálogo entre os investigadores e os respectivos sujeitos, dado estes não serem abordados por aqueles de uma forma neutra (BOGDAN; BIKLEN, 1994, p. 51).

O diálogo estabelecido entre os dados e os conhecimentos das pesquisadoras evidenciará posicionamentos epistemológicos nos argumentos contidos nas análises. O percurso do levantamento se deu a partir da análise documental dos Relatórios Anuais da EFAPE dos anos de 2018 e 2019, considerando todos os protocolos de pesquisa com anuência da instituição investigada. A presente pesquisa assume a abordagem qualitativa, caracterizada pela investigação no uso de leituras e análise dos documentos oficiais, por meio de seus relatórios anuais que sintetizam as ações de formação docente da rede estadual paulista.

Os levantamentos de dados e análises foram constituídos em duas frentes de investigação: a primeira, ocorreu durante os meses iniciais da pesquisa com foco no levantamento de dados e aprofundamentos teóricos, ampliando o conhecimento da bibliografia referente à formação docente e as contribuições metodológicas da Rede Estadual Paulista, a partir do apontamento e da compreensão da formação de docentes feita pela EFAPE; a segunda, refere-se às análises de dados que culmina neste artigo

Para organizar a análise: recortamos as ações e apontamos as instituições parceiras para o processo formativo; analisamos aspectos reflexivos para pensarmos o campo do saber da formação docente. 
A pesquisa aqui apresentada, evidencia respostas em relação a quais as instituições privadas a EFAPE faz parcerias, e assim, se junta para estabelecer as políticas públicas de formação docente.

Pensar a formação de professores é sempre pensar a formação do humano e, nessa perspectiva, se vislumbra a construção de mudanças em qualquer que seja o seu espaço de ação. Mudança entendida como aprimoramento da condição humana, como liberdade de expressão e comunicação e como desenho de possibilidades de um mundo melhor, de uma melhor convivência entre as pessoas (FELDMANN, 2009, p. 75-76).

Projetos institucionais de formação de professores abarcam perspectivas, como afirma Feldmann (2009) e podem apontar rumo a aprimoramentos amplos que consideram a condição humana. Porém, é necessário refletir se a compreensão das empresas parceiras, ao que se refere ao aprimoramento, é coerente com os princípios de formação da Secretaria e se esta coerência é condição para sua contratação para as formações.

\section{Concepção de Formação de Professores}

O pressuposto de nossos estudos parte da concepção de que a formação docente é um processo complexo, subjetivo e singular, sem padronizações, mas com concepções teóricas que as credenciam, no que diz respeito a construção da experiência e a identidade docente.

Reconhecemos a formação de professores como um processo rico, plural que se compõe pelas ações individualizadas; a identidade não se formata, mas se manifesta, se constrói, considerando o jeito único, próprio e singular de cada ser responder aos desafios do contexto pessoal e profissional com que se depara (ABREU SOUZA, 2011, p.101).

A formação requer um diálogo multidisciplinar, ao se discutir construções de conhecimentos nas mais diversas frentes de investigação do objeto. A formação de professores constitui um objeto de conhecimento complexo e desafiador num momento em que as temáticas contemporâneas nos convidam a ampliar concepções e responsabilidades, fruto de crises e transformações 
políticas, econômicas, culturais, sociais e midiáticas. Todas as mudanças impactam diretamente nos espaços escolares e nas instituições de formações, o que acaba por se criar demandas para que possamos compreender os desdobramentos no cotidiano educacional e contribuir para que novas realidades democráticas sejam criadas para uma sociedade equânime e mais justa.

Há duas frentes importantes quando apontamos para a temática da formação docente que são: formação inicial e formação continuada. Conceitualmente acreditamos na perspectiva da Formação Permanente (FREIRE,1997).

Nas últimas décadas percebemos alguns avanços no Brasil, em relação aos aspectos da legislação educacional, dada a consolidação da Constituição Federal de 1988 e, com isso, obtivemos importantes conquistas nas políticas públicas brasileiras. Em 1990, a aprovação do Estatuto da Criança e do Adolescente e, em 1996, a LDB. Criamos mecanismos de descentralização da gestão da educação pública e iniciamos Planos Municipais, Estaduais e Fóruns de Discussões sobre Educação por todo país, a fim de viabilizar o fortalecimento dos sistemas de educação brasileiros.

Vivenciamos avanços e alguns retrocessos e temos muito a conquistar em relação a formação de professores e o seu impacto direto para a qualidade da educação pública.

Nos cursos de Graduação para a formação docente, travamos discussões em relação a formação inicial, uma vez que, reconhecidamente, a Graduação é o processo de início da vida acadêmica e da profissão, porém, isto nem sempre ocorre desta forma com os alunos da Pedagogia. Temos presenciado, por vezes que esta formação pode começar após vinte anos de atuação deste profissional no seu ofício, vinte anos de prática profissional docente. Esta situação se estabelece para estes profissionais em meio a sua atuação com salas de alunos e alunas em que há uma diversidade imensa em relação a realidade, e assim, neste contexto inúmeras indagações e inquietudes nos suscitam a investigar a formação. 
Indagações como: o que é formação inicial e formação permanente? As instituições públicas têm responsabilidades com a formação docente? Os professores têm uma compreensão epistemologia do seu próprio processo de aprendizagem? Como se constrói uma experiência pedagógica crítica, autoral e autônoma? Como a academia e as redes públicas estabelecem espaços e ações para o fortalecimento da experiência e dos diálogos teóricos e metodológicos na construção do docente?

Não temos a pretensão de responder a todas estas questões, porém elas se fazem necessárias por nos permitirem vislumbrar a tessitura pela qual se constrói a formação docente.

Reconhecemos a complexa compreensão teórica que precisamos edificar para que possamos construir, de fato, caminhos reflexivos para a formação inicial e permanente. Conforme Hernández e Sancho (2007) nos afirmam, os docentes precisam ser tocados, afetados para que a experiência se converta em algo próprio, numa fonte de saber que faça sentido e se desdobre em significados:

[...] na formação, o educador aprende quando se sente tocado, quando encontra espaço para que sua experiência se converta em fonte de saber- um saber que lhe permita reconhecer-se, descobrir o outro e ser reconhecido; um saber que vá além da ação imediata e que se projete em uma atividade que o ajude a aprender consigo mesmo e, sobretudo, que o comprometa (HERNANDEZ \& SANCHO, 2007, p. 9).

Docentes são sujeitos permanentes do processo educativo e assumir a própria prática pedagógica é estabelecer diálogos reais para aprimoramentos e responsabilidades profissionais, não há receita, não há padrão de conduta, não há manuais, há práticas reais que precisam de aprofundamentos com foco na própria práxis.

Considerar a práxis do professor e sua produção de saber é aproximá-lo de uma possível reflexão sobre sua prática, o que dá possibilidades de um ressignificar de suas ações, partindo de dúvidas, vivências e experiências (ABREU SOUZA, 2002, p. 6). 
O ressignificar da prática pedagógica requer metodologias de formação que tragam esta prática para o cenário da reflexão, o que nos faz buscar ferramentas que coloquem o docente como sujeito autoral de sua prática, em um processo individual em movimento coletivo, como evidencia Freire:

A consciência do mundo e a consciência de si crescem juntas e em razão direta; uma é a luz interior da outra, uma comprometida com a outra. Evidencia-se a intrínseca correlação entre conquistar-se, fazer-se mais si mesmo, e conquistar o mundo, fazê-lo mais humano (FREIRE, 2005, p.15).

Nesta perspectiva, indagamos as formações de professores em rede pública a fim de analisar seus paradigmas e concepções e as instituições que assumem parcerias nos planos de formação oferecidos na rede pública paulista do Estado de São Paulo.

Hernández nos afirma:

A educação se concebe [...] como um processo dialético em que o sentido e o significado das estruturas de conhecimento se reconstroem na consciência histórica dos indivíduos, que tratam de dotar de sentidos suas situações vitais [...] (HERNANDEZ, 2000, p.106).

Dar sentidos as práticas desenvolvidas é uma das responsabilidades também daqueles que pensam o campo de conhecimento da formação docente, e requer a criação de espaços para que o processo dialético possa acontecer, num movimento em que as aproximações permanentes entre pessoas, sentidos e significados estabeleçam conexões e reflexões possibilitando tomadas de consciência e superações dos docentes, o que viabiliza uma prática pedagógica crítica e transformadora.

\section{Dados dos Relatórios Anuais da EFAPE}

Os relatórios anuais, documentos de análise desta pesquisa, são sínteses elaboradas pela equipe da EFAPE, descrevendo as ações realizadas pelos diversos setores da Coordenadoria. Os cursos oferecidos são denominados como centralizados e englobam ações formativas 
considerando: educação a distância com uso de vídeo conferência, web conferência e ambientes virtuais Além disso, há as atividades presenciais e em serviço que ocorrem nas 91 Diretorias de Ensino e suas 5100 unidades escolares para 245 mil servidores dos quadros do magistério, apoio escolar da Secretaria de Educação.

Os eixos formativos são divididos em três eixos: 1. Currículo e prática de ensino na Educação Básica, modalidades e atividades específicas; 2. Gestão Educacional e 3. Grandes temas da educação.

Nas ações de formação de 2018, os relatórios as dividem em cinco itens, são eles: 1.Ação centralizada ofertada pela EFAPE; 2.Ações executadas por parceiros; 3.Ações de cooperação e pesquisa; 4.Ações de formação a profissionais da EFAPE; e 5.Encontros formativos realizados pela EFAPE.

As ações de formação centralizada no relatório de 2018 estão divididas em: Encerradas - processo de certificação concluído. Encerradas - processo de certificação em processo. Em andamento - em desenvolvimento da ação. Em andamento com público externo - em desenvolvimento da ação com público externo.

As ações de formação de 2019, estão divididas nos relatórios em: Ações de Formação Centralizadas (1. Cursos; 2. Cursos - Programa Inova Educação; 3. Cursos - Executados por parceiros).

As ações de formação centralizada citadas no relatório de 2019 não têm informação sobre o andamento da ação, como descrita no relatório de 2018, porém este não será um dado para a análise.

$\mathrm{Na}$ análise estamos considerando o todo de ações, independente da situação de desenvolvimento da ação formativa. 
Quadro 1. Ações Centralizadas 2018 e 2019

\begin{tabular}{|l|l|l|}
\hline Ações Centralizadas & \multicolumn{1}{|c|}{$\mathbf{2 0 1 8}$} & \multicolumn{1}{c|}{$\mathbf{2 0 1 9}$} \\
\hline $\begin{array}{l}\text { Total de ações } \\
\text { centralizadas }\end{array}$ & $\begin{array}{l}\text { 86 cursos } \\
\text { (não há divisão da } \\
\text { classificação dos cursos) }\end{array}$ & $\begin{array}{l}\text { 32 cursos: } \\
\text { cursos diversos; } \\
\text { cursos programa inova; } \\
\text { cursos municipais }\end{array}$ \\
\hline
\end{tabular}

Fonte: [Relatórios da equipe técnica da EFAPE]

Quadro 2. Ações Centralizadas 2018 e 2019

\begin{tabular}{|c|c|c|}
\hline Ações Executadas por parceiros & $\mathbf{2 0 1 8}$ & $\mathbf{2 0 1 9}$ \\
\hline Total de ações executadas por parceiros & 110 & 38 \\
\hline
\end{tabular}

Fonte: [Relatórios da equipe técnica da EFAPE]

Quadro 3. Ações executadas por parceiros 2018 - 110 ações

\begin{tabular}{|l|c|}
\hline \multicolumn{1}{|c|}{ Parceiros } & Números de ações \\
\hline 1. Parceiros da Educação Executor & 10 \\
\hline 2. Osesp & 06 \\
\hline 3. CET & 02 \\
\hline 4. Pinacoteca & 01 \\
\hline 5. FCAV e Neuroconect Parceiros & 02 \\
\hline 6. CGEB / Embaixada Americana & 01 \\
\hline 7. CGEB / Pearson Education Brasil & 01 \\
\hline 8. CGEB/ Instituto Rodrigo Mendes & 01 \\
\hline 9. FAZESP & 04 \\
\hline $\begin{array}{l}\text { 10. CGEB / Consulado França / Associação de } \\
\text { Professores de Francês SP / APFESP - Departamento } \\
\text { de Letras Modernas USP }\end{array}$ & 02 \\
\hline 11. Elos Educacional & 01 \\
\hline 12. CGEB & 01 \\
\hline 13. Cultura Inglesa & 20 \\
\hline 14. FNDE & 09 \\
\hline $\begin{array}{l}\text { 15. Universidades (não há citação do nome das } \\
\text { universidades e não informa se são públicas ou } \\
\text { privadas) }\end{array}$ & 56 \\
\hline
\end{tabular}

Fonte: [Relatórios da equipe técnica da EFAPE] 
Quadro 4. Ações executadas por parceiros 2019 - 38 ações

\begin{tabular}{|l|c|}
\hline \multicolumn{1}{|c|}{ Parceiros } & Números de ações \\
\hline 01.Associação parceiros da Educação & 10 \\
\hline 02.Osesp & 02 \\
\hline 03.CET & 01 \\
\hline 04.Associação Pinacoteca & 01 \\
\hline 05. Parceiros & 03 \\
\hline 06.Faculdade Cultura Inglesa & 03 \\
\hline 07.POLI USP & 02 \\
\hline 08.AFPESP - DLM - FFLCH USP & 02 \\
\hline 09.COPED / ELOS / EFAPE & 01 \\
\hline 10.ICB / USP & 02 \\
\hline 11.FEA / USP & 01 \\
\hline 12.COPED / UNIFESP / EFAPE & 01 \\
\hline 13.IME / USP & 02 \\
\hline 14.UNIFESP & 01 \\
\hline
\end{tabular}

Fonte: [Relatórios da equipe técnica da EFAPE]

No relatório de 2019 há um item 2.1.3 intitulado "Ações de formação diversa" que não há no relatório de 2018, mas iremos citar os dados, visto que, nas ações, há participação de instituições parceiras. Este item, em sua totalidade, soma 38 ações de formação, sendo 19 com parcerias, são elas:

Quadro 5. Ações de formação diversa

\begin{tabular}{|l|c|}
\hline \multicolumn{1}{|c|}{ Instituição } & $\mathbf{N}^{\mathbf{0}}$ de Parcerias \\
\hline 01. Fundação Japão / São Paulo & 01 \\
\hline 02.Associação Paulista de Medicina & 01 \\
\hline 03.Hospital São Paulo & 01 \\
\hline 04.Unip & 01 \\
\hline 05.Prefeitura de São Paulo & 01 \\
\hline 06.Colégio Miguel de Cervantes & 01 \\
\hline 07.Instituto Cultural Ítalo Brasileiro & 01 \\
\hline 08.Instituto Ayrton Senna & 06 \\
\hline 09.Stem Brasil & 02 \\
\hline 10.Elos Educacional & 01 \\
\hline 11.Equipe Conviva & 01 \\
\hline 12.CITEM & 01 \\
\hline 13.Universidade Zumbi dos Palmares & 01 \\
\hline
\end{tabular}

Fonte: [Relatórios da equipe técnica da EFAPE] 


\section{Apontamentos Reflexivos}

Considerando o objetivo da pesquisa que é o de localizar as parcerias privadas que sustentam as ações formativas de professores da Rede Estadual de Educação do Estado de São Paulo nos anos de 2018 e 2019, a partir das políticas públicas desenvolvidas pela EFAPE, no ano de 2018 foram ofertadas 86 ações de formação oferecidos pela própria coordenadoria EFAPE e mais 110 ações de formação ofertadas em parceria com 15 instituições públicas (de outros setores), privadas e universidades (não há no relatório anual a informação quais seriam as universidades).

Percebemos, segundo o relatório anual, que o número de oferta de ações de formação em parceria é superior ao oferecido pela equipe interna da EFAPE, esta situação nos coloca reflexões para uma futura análise da pesquisa que envolve novas indagações. Que concepções de formação estas instituições parceiras desenvolvem em seu trabalho? A diversidade de instituições é, em sua concepção, coerente com os princípios de formação da EFAPE?

Considerando que em 2018 quinze parcerias foram feitas, são elas: 1. Parceiros da Educação Executor - devido a dados imprecisos no relatório, não localizamos o que seriam estas parcerias. 2. Osesp - órgão do governo. 3. CET Companhia de Engenharia de Tráfego - órgão do governo. 4. Pinacoteca órgão do governo. 5. FCAV - Unesp - órgão do governo junto com Neuroconect Parceiros- empresa privada. 6. CGEB - órgão do governo e Embaixada Americana - empresa pública internacional. 7. CGEB - órgão do governo e Pearson Education Brasil - empresa privada. 8. CGEB órgão do governo e Instituto Rodrigo Mendes - empresa privada. 9. FAZESP - Escola Fazendária do Estado de São Paulo - órgão do governo. 10. CGEB órgão do governo e Consulado da França - instituição pública internacional. 11. Elos Educacional - empresa privada. 12. CGEB - órgão público.13. Cultura Inglesa - empresa privada. 14. FNDE - órgão público.15. Universidades (não há citação do nome da universidade e não informa se é pública ou privada). 
A diversidade de parcerias pode, ou não, ter influências contraditórias na lógica de fortalecimento da educação pública, a pesquisa desenvolvida não se propôs a levantar as características das parcerias e da concepção de formação que as agregam, mas nos faz refletir sobre a lógica das práticas de formação destas parcerias, que certamente são diversas.

$\mathrm{Na}$ concepção e implementação de políticas, a lida com, e, a incorporação de influências diversas, muitas vezes opostas, conduz a resultados tanto de caráter intencional como não intencionais, chegando mesmo a que algumas orientações de políticas, suas normas, por exemplo, portem algumas incoerências e incompletudes que acabam se revelando em sua instauração nas realidades de destino e quanto aos objetivos visados (GATTI, 2019, p.46).

A formação dos professores e gestores e as demandas de políticas institucionais que garantam princípios pedagógicos de qualidade para o processo de ações formativas exigem que os projetos de formação tenham, de maneira clara, uma concepção de formação, a fim de ter intenções que fortaleçam a lógica da educação pública e que, podem, ser diferente da lógica das consultorias contratadas.

A formação docente e a descoberta de demandas de ações de formação nas instituições públicas abriram um nicho de mercado, em uma lógica que compreende a formação docente como um caminho de mercado, para gerar lucro, em uma perspectiva de lógica de empresa, obedecendo a racionalidade neoliberal. Esta compreensão difere da lógica de uma instituição pública que não tem por seu objetivo gerar lucro, mas fortalecer a qualidade dos serviços oferecidos a sociedade, a fim de formar profissionais da educação para um processo de trabalho desafiador num cotidiano que apresenta como realidade a diversidades. Isto nos mostra que é preciso levar:

[...] em conta o papel contínuo do Estado juntamente com o envolvimento dos atores que não fazem parte do mercado e dos interesses que não são os do mercado. $\mathrm{O}$ papel de outros grupos 'tradicionais' (professores, estudantes e administradores) tem mudado (BURTON, 2014, p. 329). 
Vivemos numa sociedade em que a consolidação dos ideais neoliberais em que a lógica de mercado, das pessoas como clientes e da empresa são concepções que crescem e emergem com os objetivos econômicos, visto que numa sociedade capitalista, o lucro é necessário. Compreender as concepções instauradas, muitas vezes, diversas e plurais pode evidenciar projetos de formação que percam os processos integrais de uma formação que se estabeleça a partir da educação pública e, por isso, compreender que a lógica da formação não é a lógica de uma empresa. “[...] a perspectiva do neopluralismo nos permite ver que, enquanto todos os grupos podem ter uma voz, alguns podem ser mais poderosos e ter mais peso do que outros junto aos que decidem" (BURTON, 2014, p. 329).

Nos dados do relatório, percebemos que a presença das instituições privadas é uma marca importante nos processos anuais desenvolvidos pela EFAPE, nos cabe, futuramente, dialogar com ações para investigar que concepção rege o trabalho pontuando cada instituição contratada.

A presença das Universidades nas parcerias de formação aponta para uma importante colaboração. E, apesar de não conseguimos identificar quais das Universidades estariam nestas parcerias, pois não há esta informação no relatório anual de 2018, a presença da academia se faz relevante, visto que é ela quem cria a ciência no país e possibilita discussões subsidiadas por teoria consolidada criticamente, mesmo considerando a diversidade acadêmica, há a certeza de que o "obscurantismo" não estará presente nas formações.

No ano de 2019, foram ofertadas 32 ações de formação oferecidos pela própria coordenadoria EFAPE, divididos em cursos diversos, cursos programa inova e cursos municipais. E mais 38 ações de formação ofertadas em parceria com 14 instituições públicas (de outros setores), privadas e universidades (identificadas). Num total de 70 ações anuais.1. Associação parceiros da Educação - não identificamos esta parceria. 2. Osesp - órgão do governo. 3. CET - órgão do governo. 4. Associação Pinacoteca - órgão do governo. 5. Parceiros - não identificamos esta 
parceria. 6. Faculdade Cultura Inglesa - empresa privada. 7. POLI USP órgão público. 8. AFPESP - DLM - FFLCH USP- órgão público. 9. COPED / ELOS / EFAPE - órgão público. 10. ICB / USP - órgão público. 11. FEA / USP - órgão público. 12. COPED / UNIFESP / EFAPE - órgão público. 13. IME / USP - órgão público. 14. UNIFESP - órgão público.

O relatório anual de 2019 apresenta uma formatação de organização de dados diferente do relatório anual de 2018. Há um item intitulado "Ações de formação diversa”. Este grupo de ação formativa estabelece parcerias diversas e as empresas privadas são maioria nas parcerias, são elas:1. Fundação Japão / São Paulo - empresa privada. 2. Associação Paulista de Medicina - órgão público. 3. Hospital São Paulo - órgão público. 4. Universidade Paulista (Unip) - empresa privada. 5. Prefeitura de São Paulo - órgão público. 6. Colégio Miguel de Cervantes - empresa privada. 7. Instituto Cultural Ítalo Brasileiro empresa privada. 8. Instituto Airton Senna - empresa privada. 9. Stem Brasil - empresa privada. 10. Elos Educacional - empresa privada. 11. Equipe Conviva - empresa privada. 12. CITEM - Coordenadoria de Informação, Tecnologia, Evidencia e Matrícula - órgão público. 13.Universidade Zumbi dos Palmares - Instituição Comunitária.

Nas ações formativas de 2019, percebemos a presença de empresas parceiras que atuam em outras redes estaduais e municipais, fazendo-nos refletir sobre a inserção crescente destas instituições privadas nas responsabilidades ligadas a projetos públicos, não nos cabe aprofundar neste artigo, a compreensão e a lógica da participação e colaboração destas parcerias, mas é afirmativo reconhecer em mais de 50\% das formações ocorrerem em parceria com instituições "parcerias” na Rede Pública Estadual Paulista.

Ainda no mesmo relatório, percebemos a presença de Universidades, nomeadas, com referência a departamentos e centros de estudos que viabiliza uma importante parceria, com a possibilidade de diálogo entre projetos públicos importante para o fortalecimento da educação pública estadual.

Compreendemos que as pesquisas desenvolvidas pelas instituições de ensino superior, sejam elas públicas ou privadas, criam um diálogo direto 
com demandas que emergem da realidade e do cotidiano do processo educativo da Rede Pública Paulista. A presença da Universidade nas parcerias é, certamente, um grande diferencial para pensar, desenvolver e avançar nas propostas de formação dos professores, pois pode promover a pluralidade de ideias e diversidades de pensamento, mostrando que: "[...] a educação é um espaço de disputa, pois comporta projetos diferentes e antagônicos do ponto de vista da sua função social defendidos para os sujeitos e para a sociedade" (CAETANO, 2018, p. 123).

Compreender os projetos de formação realizados pelas instituições parceiras é essencial o desenvolvimento de um trabalho de formação efetivamente colaborativo Para tanto, a Rede Pública de Educação Estadual Paulista conta com o Conselho Estadual de Educação que pode estabelecer os princípios norteadores para que as parcerias aconteçam, considerando, assim, os aspectos que sejam coerentes com o projeto público de formação docente para garantir a coerência das diretrizes teóricas e metodológicas dos processos.

Com relação aos interesses do capital para com o Estado, Dardot e Laval (2016, s.p.) explicam que:

O capitalismo não cresce simplesmente porque conquista novos territórios, submete populações cada vez maiores, transforma em mercadoria todos os frutos da atividade humana. Certamente, este é o modo clássico da acumulação capitalista, tal como foi analisado por Marx, Rosa Luxemburgo e Hilferding. Mas o capitalismo cresce também de outra maneira, a qual, mesmo sendo quase sempre esquecida, não é menos poderosa: a da difusão social de um sistema de regras de ação. Este sistema de normas ultrapassa largamente aquele da empresa para abraçar, por meio de um processo de ligações cruzadas, múltiplas instituições e relações sociais. Longe de ser, como se acredita, um obstáculo à extensão da lógica do mercado, o Estado tornou-se um de seus principais agentes, se não o seu principal vetor. Sob seu controle, os instrumentos de política pública herdados da gestão social-democrática e keynesiana tornaram-se, paradoxalmente, alavancas para transformar, de dentro, a lógica de funcionamento da ação pública em função de uma mudança profunda da sociedade. Por isso, é perfeitamente inepto pensar essa transformação nos termos convencionais como se viesse para limitar a intervenção governamental: ela não vem para limitá-la, mas, em certo sentido, vem para estendê-la, ou melhor, 
vem para transformar o Estado e para expandir a lógica do mercado (DARDOT; LAVAL (2016, s.p.).

Faz-se necessário compreender a lógica da economia capitalista em face do modelo neoliberal que adentra em todas as áreas e transforma sua estrutura e gera um enfraquecimento do Estado concernente à garantia dos direitos sociais e, ao mesmo tempo em que expande sua atuação em favorecimento do livre mercado.

\section{Conclusões}

Discutir as parcerias público privadas que sustentam as ações formativas de professores da Rede Estadual de Educação do Estado de São Paulo, a partir das políticas públicas desenvolvidas pela EFAPE nos levou a afirmar a demanda crescente da parceria da rede pública paulista com instituições privadas. Esta situação que evidencia uma tendência geral, explicada por LAVAL (2004), por meio dos conceitos relativos à racionalidade neoliberal que absorve também o campo da educação e, mais especificamente, da formação docente.

Percebemos, tanto nos relatórios da EFAPE de 2018 como nos de 2019, a presença da Universidade como aspecto importante para o fortalecimento do diálogo entre quem cria a ciência e quem atua diretamente nas políticas públicas para a formação dos professores da rede. Estabelecer o diálogo e assumir a formação conjuntamente são ações importantes para o fortalecimento da educação pública. Embora nos relatórios tenhamos percebido que o número de participação das Universidades é menor que a participação das empresas privadas, nos cabe salientar que a ampliação das parcerias com as Universidades seja importante para a Rede Paulista.

Novos rumos da formação docente se abrem com demandas que propõem políticas educacionais com necessidade de estabelecermos um discurso crítico para as ações formativas em rede, pois certamente, impactam diretamente na qualidade da educação pública. 
Faz-se necessário compreendermos as ações de formação aliados ao neoliberalismo como política econômica que se relaciona as estruturas do governo e do Estado. A formação de professores exige um projeto a longo prazo em que intercruzem interesses de fortalecimento da rede pública com princípios claros para que efetivem as parcerias de formação.

Reafirmamos a importância do Conselho Estadual de Educação no que se refere a criar diretrizes norteadoras para que as parcerias sejam estabelecidas o que viabilizará coerência teórica e metodológica com a rede estadual paulista. O Conselho deve garantir que as formações não se transformem em transposições de ações formativas desarticuladas, fragmentadas e que não contribuam para o fortalecimento de sua autonomia, enquanto espaço público e não empresarial.

Finalizamos reconhecendo a importância dos projetos de formação de professores da Rede Estadual Paulista para o fortalecimento de Educação Básica, afirmamos a importância da Coordenadoria EFAPE e dos membros que a constituem para a criação de políticas públicas emancipatórias, críticas e humanas nos espaços de aprendizagem dos professores com o intuito de promover:

[...] a construção epistemológica e social do conhecimento, concretizada em espaços educativos e vivenciada em movimentos de tensões e lutas pela ocupação territorial dos saberes. Nesses movimentos se mostram as delimitações dos significados dos campos do conhecimento, seus processos (discursos e métodos) e os sentidos na vida das pessoas envolvidas (FELDMANN, 2009, p.73).

Como afirma Feldmann (2009), a construção de políticas de formação na rede pública exige cuidados epistemológicos em sua concretização. Tornase necessário reconhecer que teremos limitações, mas a coerência apontará para ações que fortaleçam a autonomia, nos fazendo avançar para uma educação pública com qualidade para todos. 


\section{Referências}

ABREU SOUZA, Ana Cristina Gonçalves. Formação de Professores: da experiência do sujeito, ao sujeito da experiência. Orientadora: Ana Maria Saul. Tese (Doutorado em Educação) - Programa Educação: Currículo, PUC, SP, 2011.

ABREU SOUZA, Ana Cristina Gonçalves. Formação de professores em rede pública: marcas de uma gestão. Orientadora: Marisa Del Cioppo Elias. Dissertação (Mestrado em Educação). UBC, Mogi das Cruzes, SP, 2002.

ADRIÃO, Theresa. Dimensões e formas da privatização da educação no Brasil; caracterização a partir de mapeamento de produções nacionais e internacionais. Ciência sem Fronteiras, v.18, jan-abril, 2018, p.8 a 28.

BOGDAN, Robert; BIKLEN, Sári. Investigação qualitativa em educação: uma introdução à teoria e aos métodos. Portugal: Porto Editora, 1994.

BURTON, Guy. Teorizando o Estado e a Globalização na política e políticas educacionais. Práxis Educativa, Ponta Grossa, v. 9, n. 2, 2014, p. 315-332

CAETANO, Maria Raquel. Lógica privada na educação pública, redes globais e a formação de professores. Revista Eletrônica de Educação, São Carlos, v. 12, n. 1, jan./abr. 2018, p. 120-131.

CÓSSIO, Maria de Fátima. A nova gestão pública. Revista Educação, Porto Alegre, v.41, n.1, jan-abril 2018, p. 66-73.

DARDOT, Pierre; LAVAL, Christian. Neoliberalismo e subjetivação capitalista. $O$ Olho da História. São Paulo, n. 22, abril de 2016.

FELDMANN. Marina Graziela. Formação de Professores e Escola na Contemporaneidade. São Paulo: Editora SENAC, São Paulo, 2009.

FREIRE, Paulo. Pedagogia da autonomia: saberes necessários a quem gosta de ensinar. São Paulo: Paz e Terra, 1997.

FREIRE, Paulo. Pedagogia do oprimido. Rio de Janeiro: Editora Paz e Terra, 2005.

GATTI, Bernardete Angelina et al. Formação de professores para o Ensino Fundamental: instituições formadoras e seus currículos. In: Estudos \& pesquisas educacionais - n. 1. Estudos realizados em 2007, 2008 e 2009. São Paulo: Fundação Victor Civita, 2010.

GATTI, Bernardete Angelina. Professores do Brasil: novos cenários de formação / Bernardete Angelina Gatti, Elba Siqueira de Sá Barretto, Marli Eliza Dalmazo Afonso de André e Patrícia Cristina Albieri de Almeida. - Brasília: UNESCO, 2019.

GIMENO SACRISTAN, José. O currículo: uma reflexão sobre a prática. Porto Alegre: Artmed, 2000. 
HERNANDEZ, Fernando. Cultura Visual, Mudança Educativa e Projeto de Trabalho. Trad. Jussara Haubert Rodrigues. Porto Alegre: Artmed, 2000.

HERNANDEZ, Fernando; SANCHO, Juana Maria. A formação a partir da experiência vivida. Pátio, n. 40, 2007.

LAVAL, Christian. A escola não é uma empresa: o neoliberalismo em ataque ao ensino público. São Paulo: Boitempo, 2004.

OLIVEIRA, Romualdo Portela. de; SOUZA, Sandra Zákia Lian de. Políticas de avaliação da educação e quase mercado no Brasil. Educação e Sociedade, Campinas, vol.24, n.84, set. 2003, p.873-895.

Recebido em setembro de 2020.

Aprovado em janeiro de 2021. 